\title{
INCREASING OPPORTUNITY AND VALUE \|N THE CULTURAL INDUSTRIES A Comparative Analysis of the Successful Clusters and Implications for Hallyu
}

\author{
Hwy-Chang Moon \\ Seoul School of Integrated Sciences and Technologies \\ cmoon.snu@gmail.com
}

\begin{abstract}
Despite the growing digitalization and globalization, the industrial map of the world remains to display high-level concentration of resources and productivity in certain geographical locations called clusters. These locations such as Silicon Valley and Hollywood continue to attract entrepreneurs and large firms, enjoying strong sustainability and competitiveness. As the agglomerate of diverse entities and institutions, clusters play a significant role for improving the overall growth of the industry. This is more evident in the cultural industries where the relatively high unpredictability, expanding scale of investments, and the importance of physical location for consuming cultural contents require firms and participants to cooperate in proximity. In order to examine the importance of clusters in the cultural industries, this study first conducts a theoretical review on the role of clusters in this industry. Then, the paper analyzes the historically meaningful cultural clusters, Italy during the Renaissance and the US Hollywood of modern times, by evaluating the role of four interactive factors: firm, people, education, and government. The analysis of these two cases reveals that the interactions among the four factors significantly influence the scale and competitiveness of cultural clusters. Ultimately, the paper provides some important options for further development of the Korean wave or Hallyu by utilizing the cluster strategy.
\end{abstract}

\section{Keywords}

ABCD model; cultural cluster; ecosystem; Hallyu; Hollywood; Italian Renaissance

\section{About the Author}

Hwy-Chang Moon, Ph.D. is Chair Professor of Seoul School of Integrated Sciences and Technologies and Professor Emeritus of the Graduate School of International Studies at Seoul National University, where he also served as the Dean. He has delivered special lectures at various institutions, including Helsinki School of Economics, Keio University, and Stanford University. He is currently the editor-in-chief of the Journal of International Business and 
Economy, and he has published numerous journal articles and books on topics covering International Business Strategy, Cross-Cultural Management, Foreign Direct Investment, and Economic Development in East Asia with a focus on Korea. He has served as consultant for several multinational companies, international organizations, and governments. 


\section{INTRODUCTION}

The world has become more globalized and digitalized. The connection through the World Wide Web is growing ever thicker and the portion of global business transaction occurring through that connection has been increasing ever faster. At this rate, the total triumph of digital space over physical space may appear as decided to many people who are bracing themselves to accept the seeming inevitability, such as the demise of brick-and-mortar stores or physical business operation sites. In the future that is likely to hold even further development of internet technology, where virtual reality prevails, geographic significance may turn into one of the many relics of the past along with VCR and floppy disks.

There is a strange phenomenon to be observed, however, in the industrial map of today's world. Even as the reach of the internet continues to penetrate every deserted corner of the earth, clearly visible on the map are thick concentrations of firms, organizations, and people in certain specific geographical areas. These locations are somehow incubating a high-level expertise exchange and knowledge accumulation. Moreover, those locations are clearly anchored in tangible geophysical space, instead of cyberspace. These "geographic concentrations of interconnected companies and institutions in a particular field" (Porter, "Competitive Advantage" 78), referred to as clusters, show that geographic locations are still relevant to our modern world. Hollywood and the Silicon Valley are good examples of clusters where the dynamic interactions between various types of organizations engage in productive business activities. Although digitalization and globalization significantly lowered the geographic barriers by decreasing costs of transaction and transportation, location remains an important factor for competitiveness.

To the cultural industries, location is more important because many of the culture-related services require a place for exhibition, whether it be a film, concert, or art gallery (Gibson and Kong 542-547; Gong and Hassink 587). Although online streaming services have steadily increased throughout the cultural industries, a well-spent leisure time nonetheless includes a visit to a particular location. More importantly, an attractive leisure spot is where not only a single but a variety of enjoyable entertainment activities are available for experience. The agglomeration of cultural activities includes various industry segments from actual entertainment to dining and tourism. Therefore, due to the high spillover effects onto the other service industries, the cultural activities tend to cluster around particular locations and eventually create a cultural complex. In cultural industries, locational proximity is still relevant and significant (Lazzeretti, Boix, and Capone 1243-1245; Turok 551).

The previous studies on this topic (e.g., Lorenzen and Frederiksen 155-158; Turok 552, 563) reveal a clear dichotomy of how cities, not rural areas, were able 
to form successful cultural clusters. However, this view is overly simplistic and overlooks the more dynamic and comprehensive system of network that allows for such large agglomeration of transactions. Within clusters, there are other key contributors in addition to firms and markets that compose an ecosystem. There are universities and research institutes that promote developing and improving the cultural products and services. There are also organizations that focus on specific policy agendas to resolve relevant challenges of the stakeholders. Clusters are more than a simple concentration of business organizations, and other scholars have also emphasized the role of non-business organizations such as the role of education in understanding clusters (Taylor 178-181). In fact, clusters must be analyzed more comprehensively as organic ecosystems that include people, business, education, and government.

The approach of this paper is unique compared to that of other papers on cultural clusters that narrowly focus on the business economics of supply and demand. By examining famous cultural clusters from history to the present, namely the Italian Renaissance, Hollywood, and Hallyu, this paper analyzes how the interactions of the four factors (i.e., people, business, education, and government) has shaped the formation of successful cultural clusters. In essence, the clusters become competitive and contribute to cultural development when there is a substantial level of synergy among the four factors through their convergence and synergy.

Next, the following section briefly examines and compares the different approaches to clusters. This section pays special attention to the cultural industries and how and why clusters emerge in this particular industry. Ultimately, the integrated views of these studies are introduced as a meaningful contribution to understanding the competitiveness of cultural clusters. Then, the paper comparatively analyzes the successful cultural clusters from the past to the present. By evaluating Italian Renaissance and Hollywood according to the four factors, this research reveals how synergy is enhanced through the collaboration and convergence among these factors. Unlike the earlier two clusters, Hallyu does not have a strong geographical cluster established yet. Therefore, the following section shows a strategic implication for Hallyu to increase the advantages by utilizing other geographical or physical clusters.

\section{THEORETICAL DEVELOPMENT FOR UNDERSTANDING CREATIVE CLUSTERS}

In order to understand the changing role of clusters in both national and global economy, this paper critically reviews the preceding theoretical approaches to clusters. Existing literature on cluster formation can be mainly divided into two: 
the business-economics approach and urban economics approach. The main difference between the two approaches is the comparative role of cities and internationalization. In fact, the business-economics approach (e.g., Krugman; Porter; Moon) mainly focuses on the comparative analysis between locations in the world. However, the urban economists' explanation on clusters mainly focuses on the urbanization movements within a nation, and therefore exhibits a more domestic and microscopic view on clusters (Berg and Hassink 654-655).

Krugman explains why an increasingly larger share of the world population lives in cities and why similar economic activities are concentrated in the same locations. From his 1979 seminal study on new trade theory to the 1991 model, he divided the regions into a high-tech, urbanized core, and the less developed periphery. Krugman's idea was that firms locate themselves in the larger market to exploit economies of scale while individuals tend to move to the region with a larger population which would offer higher welfare due to a greater diversity in consumption. This is similar to how urban economics and economic geographers such as Pratt, Chapain, and Florida identify the urban development in line with the growth of creative industries.

According to Foord, a creative cluster ${ }^{1}$ is defined as a linked group of creative industries, firms, and/or cultural activities that have a spatial concentration (Foord 99). Other studies on creative clusters include Pratt's work that analyzed the cultural chain and creative production chain as the components of creative industry clusters (Pratt 1964). However, this study lacks a comprehensive view because it overlooks the interdependent network of firms with the cultural institutions and government programs. While Pratt specified the production chains in the creative clusters (1953-1974), Chapain and Propris looked into the infrastructure support and the creative class within the creative clusters (which borrows the work by Florida) that provide immediate utility to the engaging organizations (12-15). Perhaps one of the most famous scholars on this topic is Florida who introduced the concept of the creative class as the key driving force for post-industrial cities in the US (Noonan 300-303). According to this study, cities are able to attract a critical mass of creative class with high levels of talent, tolerance, and technology.

Krugman's work which linked trade theory with economic geography was useful as it provided a theoretical foundation for the development of cluster theories. As Figure 1 shows, this approach was adopted by the researchers of creative industries where geographical proximity is identified as particularly important and therefore much more relevant than any other industries. However, the research on creative industries has been limited to specifying single factors such as creative class (i.e., labor or market), infrastructure, or production chains. 


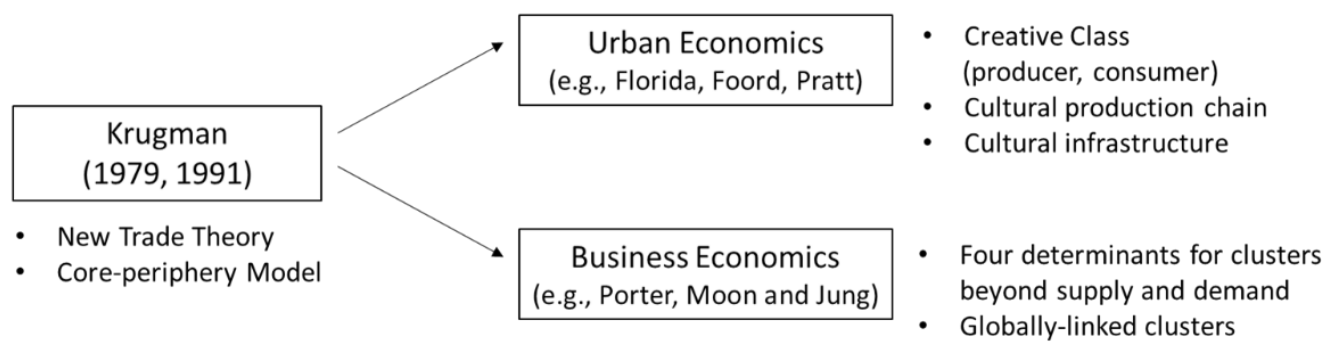

Figure 1. Theoretical Development for Clusters

In business-economics, Krugman's idea was extended notably by Porter's diamond model, and his ideas on clusters also paved the way for other regional-level analyses (e.g., Moon and Jung's global-linking cluster) to further develop. Porter's diamond model which was developed in 1990 served as a more comprehensive and systematic framework to understanding clusters. By including the related \& supporting industries and business context on top of factor conditions and demand conditions, Porter's model extends beyond the simple dichotomy of supply and demand mechanism popularized by classical economists and the researchers of cultural industries.

Despite their contribution that linked economic geography to urban development, one of the critical limitations of these approaches is that both lack an international perspective. Porter's example of cluster is narrowly focused on domestic clusters such as the Silicon Valley, Italian leather fashion, or California's wine cluster. To extend further, Moon and Jung took into account of other types of clusters that span beyond a single domestic location. They gave insights into how even within one country, different locations may be further linked. One example is the convergence of Hollywood, Disneyland, and Las Vegas as a regionallylinked cluster that is larger than a single regional cluster. The network of the three locations is an expanded form of cluster that is a great attraction for travel and tourism (Moon et al. 30).

At an international level, Moon and Jung also proved that there are internationallinking cluster (e.g., Sijori Growth Triangle integrating Singapore, Indonesia, and Malaysia) and global-linking clusters (e.g., the Silicon Valley and Bangalore). The difference between international-linking and global-linking clusters is the proximity among regions. An international-linking cluster is formed among neighboring countries whereas a global-linking cluster connects regions that are far apart as in 
the US-India example. Thus, the cluster theory has been developed by including a greater number of regions and countries.

\section{METHODOLOGY: AN INTEGRATIVE APPROACH}

According to Porter, an accurate analysis of successful performance and competitiveness must be based on more than a single, overarching element such as labor costs or economies of scale (69). In fact, success lies in the four broad attributes that constitute business environment which are factor conditions, demand conditions, related \& supporting industries, and firm strategy, structure \& rivalry (71-72). There have been various studies that used the diamond model to discuss competitiveness at the firm level (e.g., Moon and Lee), industrial level (e.g., Parc and Kawashima), and national level (e.g., Moon, Rugman, and Verbeke). For this study, the four determinants which compose the diamond model are borrowed and modified to provide a comprehensive perspective in explaining the four determinants or the ecosystem of cultural clusters.

This research is unique since it conducts a qualitative research to better understand cultural clusters from the past to the present by considering the four factors that shape successful clusters. Clusters operate in a collective action where companies benefit from local assets and institutions (Porter, "Clusters and New Economics" 88). This collective action spans beyond business and includes universities, government policies, and most importantly, the people. Since cultural industries are heavily influenced by the reception from the general public, the associative relationship between culture and people is sticky and interdependent.

The four factors are: the following: 1) businesses as the producers and distributors of culture, 2) people as the consumers of culture that play the most direct role in creating the mass culture, 3 ) educational institutions as the infrastructural ground that allow for the continuous development of soft and hard skills for culture, and 4) the government as the promoter of culture that influences through policy, structure, and system.

This study goes beyond the supply and demand approach by integrating the underpinnings of the system of network among the four factors that shape cultural clusters. Through this integrated approach, the rationale behind the linkage among the variety of industries (both related and unrelated), cooperation of business and non-business sectors, and co-opetition among businesses can be better explained and provide more comprehensive view for a successful cluster. 


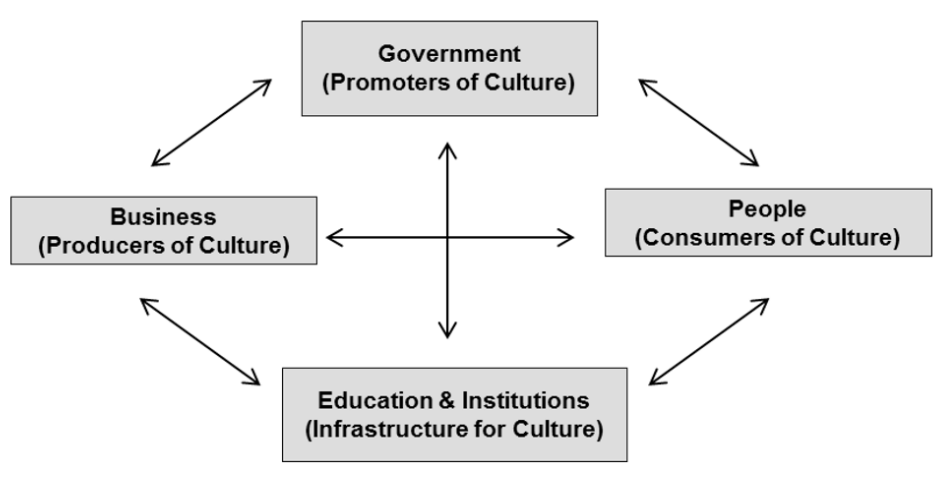

Figure 2. The Four Determinants of Cultural Cluster

\section{CLUSTERS: EVIDENCE FROM PAST TO PRESENT}

This study takes on a qualitative approach to the cultural clusters by examining two notable cultural phenomena in history. First is the Italian Renaissance during the 14th to the 16th centuries. From arts, sculpture, opera (music), to even science, this period has seen a remarkable flowering of human civilization which centered around Florence of Italy. The second phenomenon is the boom of Hollywood from the 1920 until now. The development in the motion pictures including music and arts recorded a landmark era where the town's growth through the film segment created a hub for this industry in Hollywood, California in the US. Lastly, based on the analysis of these two cases, this paper examines and provides implications for the most recent cultural phenomenon called Hallyu (the Korean Wave) as another striking transition in the global culture.

\section{The Italian Renaissance (14th - 17th centuries): Florence-Milan-Rome to the rest of Europe}

The Italian Renaissance (hereinafter, the Renaissance) is one of the most valuable cultural achievements of human kind. It is generally understood as having spearheaded the enlightenment movement across Europe, triggering other cultural awakenings such as the French Renaissance and English Renaissance. The period of the Renaissance was from the $14^{\text {th }}$ century to the $17^{\text {th }}$ century. This period marks the end of the so-called "Dark Ages," or "Middle Ages," indicating the lack 
of cultural advancement, as opposed to the classical period and following "re-birth" of culture, the Renaissance. While this "dark" perception of Middle Ages is still disputed among historians, there is no question with regard to the significance of the Renaissance period that brought back the legacies of Greek and Roman arts and sciences-which in turn brought back humans, instead of religion, into the center of the universe-in setting off a new trend in human history that led to modernity.

The birthplace of this movement was Florence which was another independent republic similar to other city-states of the Italian Peninsula. Florence was the third largest city in Europe after London and Constantinople, which was also a capital hub for banking and commerce. The city had a population of approximately 120,000 and twelve artist guilds, with around 5,00o guild members who regulated the trades that became the basis of Florence's commercial success. The lively and dynamic cultural atmosphere of Florence was made possible as the wealthy Florentines chose to boast their wealth and power by becoming patrons or supporters of artists and intellectuals. It was the wealthy merchant's support for the arts that made Florence become the cradle of the Renaissance.

Although the role of merchants or businesses in generating a cultural boom may seem natural, historically, this was not always the way of the arts before this era. The Renaissance sets itself apart from other cultural inventions in history because it was one of the earliest forms of business influence on culture. Prior to this period, arts and music were an asset and luxury only kings and royal families could possess. The Renaissance expanded the accessibility of arts as well as the diversity of its expression, as powerful merchants took patronage for artists (e.g., Medici family) (Holton 177). More commonly in the past, culture developed at the will of emperors (e.g., Louis XIV and the Palace of Versailles) or religion (e.g., Pope Leo X and the Sistine Chapel). Although the Renaissance was still mainly enjoyed by the upper-class elites, it marked a transition in cultural contents (e.g., secular subjects) and business where ownership and wealth had spread to merchants and artists, respectively (e.g., portrait of patrons instead of kings or biblical figures) (Schroeder and Bergerson 153).

\subsection{Business: Patrons, artists, and the development of technology within clusters}

Patrons or their organizations played a significant role in the Renaissance where they commanded information and technology. The growth in the patron system was an important turning point in art history, because it affected the cultural industry by binding the producers and consumers into a closer relationship. The producers

used to be the artists or the guild that operated through the artists; consumers 
were the royals or the religious leaders that granted little flexibility in contents and diversity. However, the social distance between producers and consumers of culture narrowed, while the consumer pool expanded and diversified. As the arts market was growing and established, some of the successful artists also experienced a rise in their social standings (Cole 252).

Another unique feature of the Renaissance was the emphasis on humanism. The patronage system further developed into creating a new style of production technology with the new philosophical value of humanism during the period. The steady increase in interests for science also influenced the arts where the need to draw or sculpt a human figure more realistically led to the studies on anatomy (e.g, Michelangelo, Leonardo) and other science-related subjects. Leonardo da Vinci's capabilities as engineer, anatomist, and architect demonstrate the synergistic effects created through interdisciplinary conversion during this period.

From the producers' perspective, Florence was the place that could attract producers of diverse societal backgrounds and areas of business and allow them to experiment and learn from each other's various talents and works. The fact that Michelangelo's elegantly designed windows were widely imitated throughout Florence proves that the spillover effects within the region were high where both producers of all levels and consumers of arts were large in number in establishing a cluster (Holton 179).

\subsection{People: Secularization of culture to a more diversified group of consumers within clusters}

Turning to the demand side of the cluster formation of Florence, the move toward private, personal enjoyment through the consumption of art and patronage also affected the consumption style. The arts market, in particular, became more diversified in terms of materials, techniques, styles, and contents. Whereas theological, biblical subjects filled the art pieces prior to the $14^{\text {th }}$ century, the Renaissance expanded to include natural human images that also became fashionable to portray and exhibit at home (Schroeder and Bergerson 156).

According to Schroeder and Bergerson, the patronage system in art developed in a form where the patrons took advantage of shifting artistic style to promote their desire, value, and status (154). It was also during this period where art and the art market began to be incorporated by private citizens and groups for secular means which influenced the modern business of culture. The style of religious painting in 
both religious and secular themes changed; Christ began to appear less God-like, and paintings began to picture general people attending church.

Paintings and sculptures were now being used to celebrate the affluence of merchants and bankers who were eager to celebrate the power of money (Berger 86). This was related to how one's possession of an art piece served as an advertising instrument to show off the patron's taste, prestige, and wealth (Hollingsworth 1-2). Portraits generally included the patron and his or her possessions-land, clothes, gems, works of art, furniture (Schroeder and Bergerson 160).

According to Hollingsworth, the Renaissance clients usually made several stipulations when commissioning art: " $15^{\text {th }}$ century patrons were not passive connoisseurs: they were active consumers" (1-2). First, the form of the work-such as an altarpiece, portrait, and fresco-was specified. Second, the subject matter, such as the Baptism of Christ, the Trinity, or secular scenes, was agreed on. Third, contracts were drawn that usually stated how much of the work was to be done by the hand of a particular artist, or if assistants could be used to complete the background or paint secondary figures (Baxandall 12). To evaluate, diversified and expanded Florence was in essence a $14^{\text {th }}$ century cultural cluster which possessed and further cultivated sophisticated demand for artworks and the capability to meet such demand.

\subsection{Education E Institution: Studio and apprenticeship as institutions that form the clusters}

The Big Three, or the Masters of the High Renaissance of the mid- $15^{\text {th }}$ century, are Leonardo da Vinci (1452-1519), Michelangelo Buonarroti (1475-1564), and Raffaello Sanzio da Urbino or commonly called Raphael (1483-1520). By this time, the Renaissance had already spread across Italy's city-states such as Milan, Venice, and Rome. Interestingly, the three Masters come from different regions of Italy but together designed and carved out this outstanding piece of human history along with its legacies of ever so vibrant and rich cultural assets.

Leonardo had his earlier career developed in Milan, Michelangelo earned his fame early in Florence, and Raphael became a successful painter in Umbria. Although Leonardo's first work started in Milan when Ludovico Sforza (the Duke of Milan) sought to transform Milan to rival Florence, Leonardo's apprenticeship was in Florence under the artist Verrochio. It was in Florence where Leonardo first gained an appreciation for the achievements of Giotto and Masaccio and won 
himself the chance to join the artist's guild, Compagnia di San Luca, in 1472 and receive commission from the Duke of Milan in 1482.

Michelangelo was also trained in Florence and had Lorenzo Medici as his first patron. As the longest living artist among the Big Three, he dominated the Roman art world for around forty years between 1520 and 1564. Michelangelo was apprenticed to the successful Florentine artist named Domenico Ghirlandaio. After leaving the studio, Michelangelo went to work for Lorenzo Medici. From then on, Michelangelo was acknowledged by the Catholic Church who commissioned him from 1496 to 1516 , and from 1534 to 1564 , to work in re-building what is now the Vatican.

Raphael was trained in Umbria, his hometown, with his father and the Umbrian artist, Perugino. He was already famous in the town in his early twenties, but from 1504, he moved to Florence in order to learn from Leonardo and Michelangelo on how they interpret the human anatomy and how that would be depicted in paintings. Raphael also worked in Rome from 1508 until his death in 1520 under the commissions by Popes Julius II and Leo X.

Coming from different regions, the Big Three had a common ground in training. They were all trained in a master artist's shop in Florence. Apprentices usually enter the master's shop as early as their teenage years. There is a great flexibility, but normally an apprentice stays with his master for six years on average (Black 323). The role of an apprentice starts by preparing painting materials and practicing drawing to train the eye and the hand. This studio or apprenticeship system is what we would call education and training. Being the center of the Renaissance, Florence had the infrastructure to foster soft skills of arts and hard skills of management through patrons and guilds.

\subsection{Government: The commissions from the church that expanded the cultural clusters}

After leaving Florence, the Big Three masters of arts during the Renaissance gathered again in a new common destination, Rome, at the request of Pope Leo X. Leonardo worked in Rome for only three years before he moved to France in 1516 to meet Niccolò Machiavelli and his future patron, François I who ruled France from 1515 to 1547 . Leonardo joined the French royal court but soon died in 1519. Michelangelo and Raphael stayed in Rome and worked under the commissions of various Popes (from Julius II to Pius III, Michelangelo worked with six Popes). 
As seen in the previous section, the Big Three artists were trained and hired in Florence. The earlier phase of their careers was less influenced by the government, but the power of government and religion was strong and authoritative during the $14^{\text {th }}$ and $15^{\text {th }}$ centuries in Italy. In addition, the fact that the three artists thrived at a time when Rome was trying to re-build its Catholic Church under the leadership of Nicholas V in 1447 would be another inevitable reason for this influence.

Understanding how the spread of the Renaissance shifted from Florence to Milan then finally to Rome is meaningful to draw a comparative analysis of how a cluster expands. Although the cluster of the Italian Renaissance was initially shaped largely by government influence, it eventually succeeded in expanding the influence to other regions of Italy, then to France and the rest of Europe. According to the four-stage approach to clustering of this paper, the Italian Renaissance succeeded in forming a regional-linking cluster. The Europe-wide influence of the Italian Renaissance was remarkable, however, for this cultural spread to be established as international- or global-linking cluster; there should be more extensive and intensive transfer of knowledge and resources in the production of arts and culture.

The political stability (e.g., the Peace of Lodi in 1454 between Milan, Naples, and Florence), urbanization, and active international trade of Florence have allowed this place to reap the fruit of the Renaissance. The main contributor of this success was the Medici family, and many art historians believe that this family provided the catalyst for the rebirth of arts in Italy. According to Cole, "Florence entered a period of unrivaled cultural vitality under the patronage of the Medici family that granted easy exchange of ideas between politicians, artists, and scholars" (12).

\section{Hollywood (1910s - the present): From Hollywood, Los Angeles and Las Vegas to rest of the world}

Hollywood produces only a fraction of the number of films made in the world, but the region takes $75 \%$ of the total world revenue on films, and $50 \%$ of its earnings come from global markets (MPAA). It is hard to imagine with today's glamor and fancy that Hollywood represents that Hollywood was a thriving agricultural community until the late $19^{\text {th }}$ century. By 1900, Hollywood only had a population of 500 when the neighboring Los Angeles had reached 100,000 along with its orange groves. However, from the early 1990s, filmmakers began to move to the Los Angeles area to avoid the strict rules imposed by Thomas Edison's Motion Picture Patents Company in New Jersey. Edison owned most of the movie-making patents and independent filmmakers were often sued by Edison, halting all productions on the way. 
In need of an escape and drawn by the beautiful weather and beaches of California, filmmakers began to settle in Los Angeles. Agents who heard the news of Edison company's lawsuit could find enough time to flee to Mexico to escape legal conflicts. Biograph Company pioneered in taking this fleet and after filming in Los Angeles, the company explored the neighboring areas including Hollywood where they shot their first film titled In Old California in 1910. The first motion picture studio was built in 1911 by Al Christie, and other movie studios began to hurdle since then. By 1919, Hollywood had transformed to represent the US cinema; the famous Hollywood logo on top of Mount Lee was erected in 1923 which has become a trademark owned by the Chamber of Commerce.

\subsection{Business: The diversification of the Hollywood cluster}

From the end of the silent film era around 1927 to 1948, the Hollywood movie studio system controlled where films were shown across the country. Five major Hollywood-area studios owned large, grand theaters where they would show only movies produced by their studios and made with their contracted actors (e.g., block booking, blind bidding). These studios were Paramount, RKO, 2oth Century Fox, Metro-Goldwyn-Mayer (MGM), and Warner Bros. However, in 1948, the US Supreme Court ruled that studios could not own their own theaters and transformed the existing practices that only showed films made by their own studios and only with actors who had exclusive contracts with those studios.

The development of the film industry was carried out in three stages which can be classified according to the differences in leadership characteristics. First era was marked with directors and stars. Directors began to receive greater recognition for using and trademarking personal styles in the creation of their films, which previously in history had not been possible due to limitations in filmmaking technology. On the other hand, movie stars began to receive greater fame due to increased publicity and shifts in American trends to big screen. However, as the growth of the film industry weakened for reasons such as the invention of TV, the rise of high-budget films, and increasing cost of technology, the leadership of directors and stars was replaced by that of the studios that extensively diversified to managing printing, distributing, and advertising.

The film industry is different from other industries in that it has an extremely complex network of value chain activities (Lee 99). Furthermore, as a cultural business, the risk of anticipating the movie-goer's taste is high as the famous quote "nobody knows" implies (Caves 85-86, 146-147). This shifted the role of arts creators (e.g., film directors) to the studios (e.g., Hollywood executives). This 
transition shows that strategy and business administration may be more critical to the sustainability of film productions.

The third stage of development in the Hollywood system features the intensification of partnership between major studios and smaller firms or even outside Hollywood. According to studies (e.g., Coe, EIDC, Monitor), the number of film producers outside of Hollywood has been steadily increasing since the $1980 \mathrm{os}$ (e.g., satellite production locations). There is also an increasing number of co-productions throughout the world (e.g, US-China co-production, Hollywood-Vancouver, Canada) (VangLauridsen and Chaminade 18). Scott argued that the new Hollywood production system is divided into two segments that comprise the majors and their cohorts of allied firms and the mass of independent production companies (958-961). The satellite locations of Hollywood films beyond the original region can be interpreted as decentralized or de-clustering. However, as Moon and Jung had pointed out, this may be a phase of how Hollywood cluster is connecting with other regions by exchanging knowledge and resources through linking regionally or globally.

\subsection{People: Film as a popular culture that is inclusive of all people}

Perhaps the biggest difference between Hollywood and the Italian Renaissance is its inclusivity. The film industry established itself as a popular culture (or pop culture) where anyone could produce and consume. The development of pop culture came near the end of the World War II when major cultural and social changes brought mass media innovations. Together with the spread of democracy during this period, the pop culture, which was seen as low culture of the poor education or low class (Chapman 243), had become elevated in its status and consumed by everyone.

Since the 1950s, other art forms became a commodity, subject to market forces and consumer behavior processes (e.g., Watson 5-7; Witkowski 640-647). The average family grew in wealth and created new social trends. In particular, the invention of TV shifted the viewer from going to theaters to staying at home to watch through TV channels. Temporarily, this caused a major decline in movie theater attendance, but Hollywood adapted and began to produce films for TV. This marked the integration and expansion of film to TV industry practiced by major film studios in Hollywood.

The invention of video tapes and DVD discs harnessed the profits for Hollywood filmmakers once more. Since the 1990s, the cost of producing films has become strikingly high as the demand for more high-tech effects has grown. The film 
industry became more polarized as studios focused on tent-pole movies that are higher-budget and higher-profit films (Küng 82-83; Lampel, Shamsie, and Lant 179184). The technology-embedded films also expanded the consumer base, because the contents could lower the nationalistic elements of the US. The superhero movies which are popular throughout the world are high-tech films that contain less words and cultural symbols in which global audiences can enjoy without experiencing cultural and language barriers.

\subsection{School: The role of competitive universities in the cluster}

While the three Renaissance men were trained in Florence by serving as apprentices under their masters, the modern-day equivalent are the universities and educational institutions that generate knowledge and skilled labor that continue to advance the film industries in Hollywood. A successful cluster requires a convergence of business and educational institutions (e.g., Stanford University in the Silicon Valley; Moon 17-18).

Near Hollywood, there are many schools that provide programs in cinematic studies such as the University of Southern California's Cinematic Arts, UCLA's School of Theater, Film, and Television, American Film Institute, and Chapman University. These universities enjoy the benefit of proximity to Hollywood by finding various opportunities to collaborate with the Hollywood cluster on various levels. From financial grants to partnership programs in creating screenwriting and testing technology, there is a wide exchange of knowledge, skills, and technology through partnerships. The California Institute of the Arts was founded by Walt Disney and produced famous producers and artists such as John Lasseter, Brad Bird, and Tim Burton.

The dynamic and active engagement of the film industries with the various education and training institutes has fostered a spirit of learning in the Hollywood cluster. There is an increasing number of global cooperation among these institutions which will gradually expand the cluster geographically and globally. Chapman University sends students to shoot in Asian countries such as Korea, Taiwan, and China through its travel and exchange program. If these programs expand continuously, and the foreign regions eventually form a cluster of their own, the cultural cluster that links Hollywood with others would benefit from enhanced synergy and competitiveness. 


\subsection{Government: Enhancing attractiveness to maintain the cluster}

The last force that shapes the cultural industries, and in the most sensitive ways in many regards, is the government. Throughout history, governments have often attempted to use the cultural industries as their instrument to realize their political agenda, by using them to advertise propaganda. Similar to how the Renaissance was used to impart religious values by Rome, Hollywood also receives criticisms for its longtime partnership with the government for instigating American values or military power. This paper will step aside from this sensitive topic and focus more on the subsidies (e.g., tax incentives, non-financial benefits) that have influenced Hollywood and the government at both state and national levels.

The subsidies to Hollywood have begun to increase since 2002, and this was mainly given to prevent the so-called runaway productions in the 1990 s that took place outside the US, such as Canada, to save costs. According to studies, the number of US consumption of movies and TV rose three times between 1990 and 1998, but more than eight in ten of those productions were made in Canada. The $20 \%$ decline in the Canadian dollar and tax rebates from the government allowed firms to reduce the cost of filming by $20 \%$ compared to the productions in the US ("When Will States").

In particular, the state of California has increased subsidies in order to stay competitive and attractive compared to the other states that compete for filming locations. Since the 20oos, states began to grant the Motion Picture Incentives (MPIs) through a variety of grants, cash rebates, and special privileges to invite movie producers to shoot films in their municipality. Film producers easily received free access to government property or even military technology as long as the correct patriotism was shown. By 2012, forty-five states grant MPIs, which led California and New York, the two giant regions in this industry, to increase their incentives as well. California increased its tax credits from US\$100 million to US\$ 330 million, while New York increased to US\$ 420 million a year (Los Angeles Times, 06/27/2018).

\section{IMPLICATIONS FOR CREATING A CLUSTER FOR HALLYU: CONVERGENCE AMONG DIVERSE FACTORS AND INDUSTRIES}

In recent years, the Korean wave or Hallyu, has been tremendously successful. Particularly, the recent trend in global pop music has undergone notable changes where the dominance of US and British pop has gradually shifted to Asia's pop music. Korea's K-pop especially began to gain remarkable recognition from the 
20oos (Howard vii-xi). However, the key success factor of Hallyu is different from that of other historical cases of the Renaissance and Hollywood. Many studies emphasized the role of entertainment companies, namely the Big Three-SM Entertainment, YG Entertainment, JYP Entertainment-and most recently, the Big Hit Entertainment that has continuously succeeded in creating the global flow of K-pop (Jeon and Song 33-34; Seo 56; Kim 160-162). In fact, the success factor of Hallyu is the company-based growth strategy of these entertainment firms, rather than a regional cluster in Korea.

\section{Current Practice of Hallyu as a Company-based Agglomeration}

SM Entertainment is the largest entertainment company in Korea which has led the growth of the cultural industries in Korea. The company was founded in 1995 by Lee Soo-man and was listed on Korea's stock market in April 2000 to meet the investment conditions of Japan. Forbes Asia describes SM as the "company that created K-pop." SM has various business units in entertainment (music, production, concert, management) and commerce \& amusement (SMTOWN gift shops and studios, café/market, restaurant, winery, magazine, and travel agency).

YG Entertainment is the second most profitable entertainment firm in Korea that was founded in 1996 by a member of a famous boy group in Korea. The founder Yang Hyun-suk and his brother Yang Min-suk successfully managed the company to diversify into areas of record label, talent agency, music production, and concert business along with other non-music related services such as fashion apparel, food, golf management agency, and cosmetic brand.

JYP Entertainment was founded in 1997 by Park Jin-young, and the company currently operates in businesses of record label, talent agency, and music production and publishing. It is perhaps the least diversified among the Big Three firms of K-pop, however, JYP is nevertheless the entertainment company that had the first glimpse of global-scale popularity (i.e., both Asia and the US) with its former singer, Rain, until 2007. Rain was the first Korean star to perform at Tokyo Dome; he was the first and so far the only Korean entertainer to be included in the Time magazine's 100 Most Influential People Who Shape Our World.

The boy group, BTS, by the Big Hit Entertainment made a huge success by winning awards from the US Billboard most recently in 2017 and 2018. With this boy group, the Big Hit has emerged as the new strong leader of K-pop with a growth rate of $214 \%$ in net profits at US\$ 30.3 million which surpassed all of the Big Three entertainment firms in Korea (SM's US\$ 10.1 million, YG's US\$23.5 million, 
and JYP's US\$ 18.2 million) (Herman). The company was founded in 2005 by Bang Si-hyuk who used to compose songs at JYP until he left to establish a company of his own.

These four entertainment companies have propelled and catalyzed the spread of Hallyu to the world. The advantage of this company-based approach is an internal integration of the four factors (i.e., business, people, education, and government) that were relevant to the successful regional cluster. On top of the active creation of markets for teenage culture, K-pop producers have diligently systemized the idol training system (average of 4-6 years) which replaces the educational institutions' role and they have sided with the Korean government to promote Korea's soft power through cultural contents (Shin and Kim 264-266). Korea's entertainment firms have directly taken leadership in the four factors rather than depending or waiting for a regional cluster to be created. In essence, this company-based strategy can be faster and more efficient than the regional cluster strategy in the initial stage of growth.

\section{Implications for Global-linking Cultural Cluster for Sustainable Competitiveness}

Although this company-based strategy has made possible the fast and successful performance in the cultural industries, its sustainability is questionable as the global competition intensifies and its scope expands. In order to sustain their success, the Korean firms need to establish a physical cluster in Korea to interact with other firms and industries for enhancing competences through active sharing and creative benchmarking. There are two main solutions which can be useful for the long-term sustainability and success of Hallyu: the first is to create Hallyu's own cluster, and the second is to link with other regional clusters.

Since the first solution to create its own cluster will take time, the second option to participate in other clusters such as Hollywood and Bollywood is going to be a more immediately realizable step. In fact, in June 2018, Korea's one of the largest total entertainment conglomerates, CJ E\&M (hereinafter CJ) announced its plan to move to Hollywood to produce and distribute films. CJ has gained competitiveness in creating dramas and K-pop contents mainly for the Asian audiences, and the company has expanded its business from film distributor and exhibitor (i.e., CGV) inside Korea. Together with its contents creating capabilities from TV dramas, the company is moving toward the motion picture productions. Through investing in Hollywood, CJ would be able to form a global-linking cluster where the transfer of 
resources, capabilities, technology, and talents would eventually impact the growth of the four factors in the clusters.

Utilizing other regional clusters also hints at integrating different sectors within the cultural industries. For instance, Hollywood and the US pop music industry are highly interactive and integrated. Since music and sound component constitutes a big part of filmmaking, Hollywood film productions include the participation of big music labels such as Sony or Warner Music Group. There are many other smallto-medium-sized labels that differentiate themselves by specializing in particular sound effects or divisions in music and sound productions. Korea's cultural industries can expand by integrating the well-established but independent sectors in film and music. While the one-source-multi-use strategy in Korea's cultural industries is prevalent, integrating and networking with diverse cultural areas will allow the creation of great synergy and competitiveness. Figure 3 represents how cultural clusters can be explained by their degree of internationalization and diversity throughout the ecosystem (e.g., business versus all four factors).

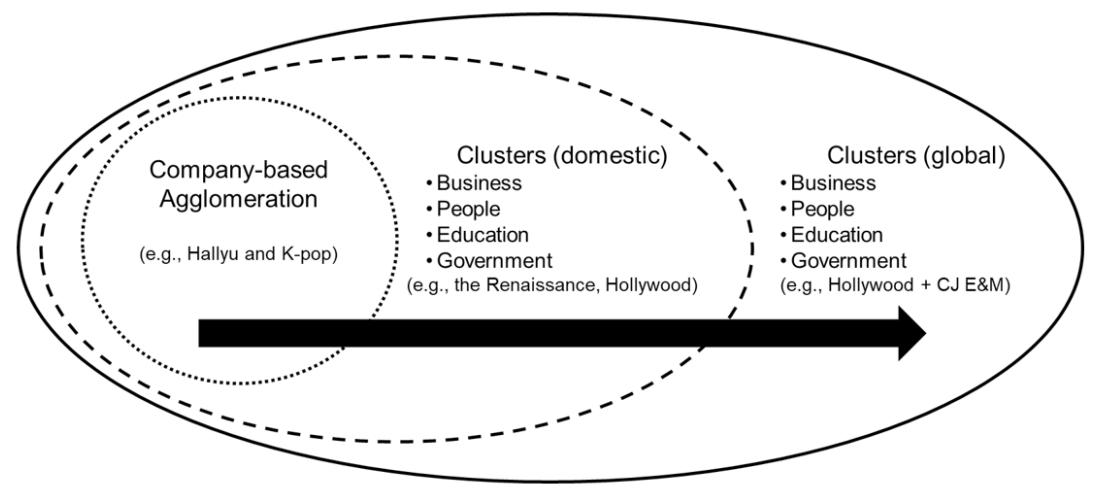

Figure 3. The Process of Company-based Agglomeration to Global-linking Cluster

\section{CONCLUSION}

Historically, the clustering in the cultural industries started in urban areas where the leisure time of the higher-income group increased. With technology advancement, industrial transformations allowed for broader and higher level of interests in culture and the arts. In particular, the third industrial revolution gave rise to a creative class (i.e., high-income group in urban areas that shares great interests and tastes in creative, artistic work). The connection between cultural 
industries and urban development has led scholars of economic geography and urban economics to broaden the scope of studying the industries, providing the theoretical background for the development of cultural clusters.

Together with the government initiatives that saw cultural clusters as a strategic industry to foster innovation, employment, and a nation's industrial transformation, most of the earlier studies on cultural clusters were approached by economists who tended to look at how the supply and demand conditions of cities influence successful cultural clusters. According to this view, industrialization has pulled knowledgeable, wealthy class to the cities where there was an increasing establishment of entertainment exhibits. This naturally attracted the creative class (i.e., the artists) to the cities, expanding the scale and scope with time. The urban areas also benefited from exponential population growth which meant a larger pool of consumers for culture and the arts.

This study conducted a systematic analysis by integrating the role of business, people, education, and government to examine the historically meaningful cultural clusters, the Italian Renaissance and Hollywood. These two are worth analyzing as the most successful cases of cultural clusters with their overarching influence on the different corners of the society. However, unlike the two famous cases of the Renaissance and Hollywood, Hallyu has taken a unique route to success. The former was through establishing regional, geographical cluster; the latter, a company-based growth strategy. Each has its own strengths and weaknesses. The regional cluster is more stable once it is well established; otherwise, it is influenced by exogenous factors such as the government and outside institutions which may not often be efficient. By contrast, the company-based strategy is efficient and fast as the company designs and controls the entire value chain; however, it may not be sustainable as an individual firm cannot control all of the related factors that become critical to the sustainability of the firm's performance. The Korean firms in the cultural industries have been quite successful with their company-based strategy. For further and sustainable success, however, they also have to create new clusters or tap into existing regional clusters. These two strategic directions can help enhance and sustain the competitiveness of not just the Korean firms but also the firms in other countries. 


\section{Acknowledgement}

This work was supported by the Laboratory Program for Korean Studies through the Ministry of Education of the Republic of Korea and the Korean Studies Promotion Service of the Academy of Korean Studies (AKS-2015-LAB-2250003). 


\section{Note}

1. The term creative clusters is used in this paper only when it refers to the direct usage by a particular scholar. To clarify, both of the terms cultural and creative have been simultaneously used in the existing studies. The choice of words varies by governments. For instance, European countries adopted the term creative while East Asian countries such as Korea and Japan use both culture and contents. An international institution such as UNESCO uses the term cultural. The main difference between the two dominant trends is that creative industries put an emphasis on a more copyright-based economic value while the cultural industries concept embodies both the social and economic value added (refer to Lee 24-26 for more explanations). 


\section{Works Cited}

Baxandall, Michael. Patterns of Intention: On the Historical Explanation of Pictures. Yale UP, 1985.

Berg, Su-Hyun, and Robert Hassink. "Creative Industries from an Evolutionary Perspective: A Critical Literature Review." Geography Compass, vol. 8, no. 9, 2014, pp. 653-664.

Berger, John. Ways of Seeing. Penguin, 1972.

Black, Robert. "Italian Renaissance Education: Changing Perspectives and Continuing Controversies." Journal of the History of Ideas, vol. 52, no. 2, 1991, pp. 315-334.

Chapain, Caroline, and Lisa De Propris. "Drivers and Processes of Creative Industries in Cities and Regions." Creative Industries Journal, vol. 2 no.1, 2009, pp. 9-18.

Cole, Bruce. Italian Art, 1250-1550: The Relation of Renaissance Art to Life and Society. Harper \& Row, 1987.

Foord, Jo. "Strategies for Creative Industries: An International Review." Creative Industries Journal, vol. 1, no. 2, 2009, pp. 91-113.

Florida, Richard. Cities and the Creative Class. Routledge. 2005.

Gibson, Chris, and Lily Kong. "Cultural Economy: A Critical Review." Progress in Human Geography, vol. 29, no. 5, 2005, pp. 541-561.

Gong, Huiwen, and Robert Hassink. "Exploring the Clustering of Creative Industries." European Planning Studies, vol. 25, no. 4, 2017, pp. 583-60o.

Herman, Tamar. "BTS's Label, Big Hit Entertainment, Saw Huge Gains in 2017." Forbes, 22 Mar. 2017, www.forbes.com/sites/tamarherman/2018/03/22/bts-label-big-hitentertainment-more-than-doubled-its-revenue-in-2017/\#31153c4b3d31. Accessed 15 Nov. 2018.

Hollingsworth, Mary. Patronage in Renaissance Italy: From 1400 to the Early Sixteenth Century. Johns Hopkins UP, 1994.

Holton, Robert J. "Max Weber, Rational Capitalism, and Renaissance Italy: A Critique of Cohen." American Journal of Sociology, vol. 89, no. 1, 1983, pp. 166-180.

Howard, Keith. Korean Pop Music: Riding the Wave. Global Oriental, 2006.

Jeon, Hyeong-yeon, and Song, Kee-ran. "Exploratory Study for Cultural Management Cooperative System of K-pop: Through Perception of Chinese Urban Youths about K-pop." [in Korean]. Humanities Contents, no. 26, 2012, pp. 33-71.

Kim, Young-ah. "Research of the Change in Korean Popular Music after the 1990s - Based on SM Entertainments and JYP Entertainments." [in Korean]. Humanities Contents, no. 12, 2008, pp. 159-175.

Krugman, Paul R. "Increasing Returns and Economic Geography." Journal of Political Economy, vol. 99, no. 3, 1991, pp. 483-499.

--. "Increasing Returns, Monopolistic Competition, and International Trade." Journal of International Economics, vol. 9, no. 4, 1979, pp. 469-479.

Küng, Lucy. Strategic Management in the Media: Theory to Practice. Sage, 2008. 
Lampel, Joseph, Jamal Shamsie, and Theresa K. Lant. The Business of Culture: Strategic Perspectives on Entertainment and Media. Psychology Press, 2006.

Lazzeretti, Luciana, Rafael Boix, and Francesco Capone. "Do Creative Industries Cluster? Mapping Creative Local Production Systems in Italy and Spain." Industry and Innovation vol. 20, no. 8, 2012, pp. 1243-1262.

Lee, Yeon W. The Strategy for Sustainable Competitiveness: Theoretical Extension and Application to Global Conglomerates in Cultural Industries. Unpublished Ph.D. Dissertation, Seoul National University, 2018.

Lorenzen, Mark, and Lars Frederiksen. "Why Do Cultural Industries Cluster? Localization, Urbanization, Products and Projects." Creative Cities, Cultural Clusters and Local Economic Development, 2008, pp. 155-179.

Moon, Hwy Chang. "The Strategy for Korea's Economic Success: Innovative Growth and Lessons from Silicon Valley." [in Korean]. Review of International and Area Studies, vol. 26, no. 3, 2017, pp. 1-33.

Moon, Hwy Chang, and Dong-hun Lee. "The Competitiveness of Multinational Firms: A Case Study of Samsung Electronics and Sony." Journal of International and Area Studies, vol. 11, no. 1, 2004, pp. 1-21.

Moon, Hwy Chang, and Jin Sup Jung. "Northeast Asian Cluster through Business and Cultural Cooperation." Journal of Korea Trade, vol. 14, no. 2, 2010, pp. 29-53.

Moon, Hwy Chang, Jin Sup Jung, Wenyan Yin, Jimmyn Parc. "The Sources of Competitiveness of a Leisure City: Case Analysis of Some Successful Leisure Cities and Implications for Chuncheon." [in Korean]. Journal of Leisure Studies, vol. 5, no. 2, 2007, pp. 24-39.

Moon, Hwy Chang, Alan M. Rugman, and Alain Verbeke. "A Generalized Double Diamond Approach to the Global Competitiveness of Korea and Singapore." International Business Review, vol. 7, no. 2, 1998, pp. 135-15o.

"Movie Ticket Sales Set Global Record \$40.6 Billion in 2017 but Dipped in U.S. and Canada." Los Angeles Times, 4 Apr. 2018, www.latimes.com/business/hollywood/la-fi-ct-mpaaannual-report-20180404-story.html. Accessed 15 Nov. 2018.

MPAA (Motion Pictures Association of America). "2018 Research Report: The Economic Contribution of the Motion Picture \& Television Industry to the United States." Feb. 2018. www.mpaa.org/research-docs/the-economic-contribution-of-the-motionpicture-television-industry-to-the-united-states/. Accessed 15 Nov. 2018.

Noonan, Caitriona. "Professional Mobilities in the Creative Industries: The Role of 'Place' for Young People Aspiring for a Creative Career." Cultural Trends, vol. 24, no. 4, 2015, pp. 299-309.

Parc, Jimmyn, and Nobuko Kawashima. "Wrestling with or Embracing Digitization in the Music Industry: The Contrasting Business Strategies of J-pop and K-pop." Kritika Kultura, vol. 30/31, 2018, pp. 23-48.

Pratt, Andy C. "The Cultural Industries Production System: A Case Study of Employment Change in Britain, 1984-91." Environment and Planning-A, vol. 29, no. 11, 1997, pp. 1953-1974.

Porter, Michael E. "Clusters and the New Economics of Competition." Harvard Business Review, vol. 76, no. 6, 1998, pp. 77-90. 
-.. Competitive Advantage of Nations: Creating and Sustaining Superior Performance. Free Press, 2011.

Seo, Jeong-hwan. "Study on the entertainment marketing strategies of K-pop - With focus on the technique of producing hook songs." [in Korean]. Journal of Arts Management and Policy, vol. 24, no. 11, 2012, pp. 55-72.

Scott, Allen. "A New Map of Hollywood: The Production and Distribution of American Motion Pictures." Regional Studies, vol. 36, no. 9, 2002, pp. 957-975.

Schroeder, Jonathan E., and Janet L. Borgerson. "Innovations in Information Technology: Insights from Italian Renaissance Art." Consumption, Markets and Culture, vol. 5, no. 2, 2002, pp. 153-169.

Shin, Solee I., and Kim, Lanu. "Organizing K-pop: Emergence and Market Making of Large Korean Entertainment Houses, 1980-2010." East Asia, vol. 30, no. 4, 2013, pp. 255-272.

Taylor, Calvin. "Developing Relationships between Higher Education, Enterprise and Innovation in the Creative Industries." Entrepreneurship in the Creative Industries: An International Perspective, edited by Colette Henry, Edward Elgar, 2007, pp. 178-196.

Turok, Ivan. "Cities, Clusters and Creative Industries: The Case of Film and Television in Scotland." European Planning Studies, vol. 11, no. 5, 2003, pp. 549-565.

Vang-Lauridsen, Jan, and Cristina Chaminade. "Global-local Linkages, Spillovers and Cultural Clusters: Theoretical and Empirical Insights from an Exploratory Study of Toronto's Film Cluster." Industry \& Innovation, vol. 14, no. 4, 2007, pp. 1-38.

Watson, Peter. From Manet to Manhattan: The Rise of the Modern Art Market. Random House, 1999.

“When Will States Get Smart and Stop Subsidizing Movies?" Los Angeles Times, 13 Mar. 2017, www.latimes.com/opinion/op-ed/la-oe-malanga-hollywood-subsidies-20170813story.html. Accessed 16 Nov. 2018.

Witkowski, Terrence H. "The Art of Consumption." Advances in Consumer Research, edited by Eric Amould and Linda Scott, Association for Consumer Research, vol. 26, 1999, pp. 640-647. 